\title{
MUSEU ESCOLAR: SENTIDOS, PROPOSTAS E PROJETOS PARA A ESCOLA PRIMÁRIA (SÉCULOS 19 E 20)
}

\author{
Marilia Gabriela Petry \\ Universidade do Estado de Santa Catarina - Brasil. \\ Vera Lucia Gaspar da Silva \\ Universidade do Estado de Santa Catarina - Brasil.
}

Resumo

O presente artigo tem como objeto de estudo os museus escolares introduzidos em escolas brasileiras no final do século 19 e ao longo do século 20. Sua motivação partiu da constatação que existiram diversas propostas, formas de operacionalizar e diferentes objetos nomeados museus escolares. Buscamos, a partir disso, identificar diferenças em impressos pedagógicos e na legislação do ensino, privilegiando o Estado de Santa Catarina como contexto de referência para mobilizar o segundo tipo documental. Como resultado, chegamos a seis acepções que assumem formatos distintos, embora visem ao mesmo objetivo: tornar os meios de ensino mais concretos. Apresentar tais acepções é o objetivo principal deste artigo, que se insere na discussão acerca dos materiais de ensino e de sua introdução na escola.

Palavras-chave: museu escolar, museu pedagógico, objetos escolares, espaço escolar.

\section{SCHOOL MUSEUM: MEANINGS, PROPOSALS AND PROJECTS FOR ELEMENTARY SCHOOL $\left(19^{\text {th }}\right.$ AND $20^{\text {th }}$ CENTURIES)}

\section{Abstract}

The present article study objects are the school museums introduced into Brazilian schools in the end of the $19^{\text {th }}$ century and during the $20^{\text {th. }}$ Its motivation was based upon the finding of several proposals, ways of operationalize and different objects named school museums. From this the identification of differences in pedagogical texts and educational legislation has been sought, privileging the state of Santa Catarina as referential context to mobilize the second documental type. As a result, six meanings have been reached, each taking a distinct format although aiming the same goal: To make educational means more concrete. To present such meanings is the main objective of this article, which is inserted in the discussions about teaching materials and their introduction in schools.

Key-words: school museum, pedagogical museum, school objects, school space. 


\section{MUSEO ESCOLAR: SENTIDOS, PROPUESTAS Y PROYECTOS PARA LA ESCUELA PRIMARIA (SIGLOS 19 Y 20)}

Resumen

El objeto de estudio del presente artículo son los museos escolares introducidos en las escuelas brasileñas al final del siglo 19 y a lo largo del siglo 20. El estudio fue motivado por la constatación de diversas propuestas, formas de operacionalizar y diferentes objetos denominados museos escolares. Buscamos, entonces, identificar diferencias en impresos pedagógicos y en la legislación de la enseñanza, privilegiando el Estado de Santa Catarina como contexto de referencia para movilizar el segundo tipo documental. Como resultado, llegamos a seis acepciones que asumen formatos distintos, aunque objetiven lo mismo: tornar los medios de enseñanza más concretos. El principal objetivo de este artículo es presentar tales acepciones, que se insertan en la discusión acerca de los materiales de enseñanza y su introducción en la escuela. Palabras-clave: museo escolar, museo pedagógico, objetos escolares, espacio escolar.

\section{MUSÉE SCOLAIRE : SENS, PROPOSITIONS ET PROJETS POUR L'ÉCOLE PRIMAIRE (19 ${ }^{\text {ème }}$ ET $20^{\text {ème }}$ SIÈCLES)}

\section{Résume}

Cet article a pour objet d'études les musées scolaires introduits dans les écoles brésiliennes à la fin du $19^{\text {ème }}$ siècle et au cours du $20^{\text {ème }}$ siècle. II a été écrit en raison du constat de l'existence de plusieurs propositions, de différentes formes d'opération et de divers objets nommés musées scolaires. Nous avons cherché, à partir de ce constat, à identifier des différences dans des imprimés pédagogiques et dans la législation de l'enseignement, en focalisant l'état de Santa Catarina, en tant que contexte de référence, afin de mobiliser le deuxième genre documentaire. Nous avons abouti à six acceptions qui prennent différentes formes, malgré le fait qu'elles aient le même but: rendre plus concrets les moyens de l'enseignement. Présenter ces acceptions constitue le principal objectif de cet article qui intègre la discussion concernant les matériels d'enseignement et leur introduction à l'école.

Mots-clé: musée scolaire, musée pédagogique, objets scolaires, espace scolaire. 


\section{Introdução}

materialidade escolar tem ganhado evidência nos estudos em história da
educação, tanto no caso brasileiro, quanto estrangeiro. São produções e
pesquisas que buscam, de modos distintos, compreender a constituição da escola pelo seu aspecto material, seja pela análise de sua arquitetura, de livros e cadernos a ela destinados, seja pelo estudo de objetos particulares, como quadros negros, carteiras, instrumentos de laboratórios, entre outros artefatos de destinação escolar. Entre os inúmeros utensílios pensados para as escolas, encontram-se os museus escolares, não apenas como objeto, mas também como espaço físico.

Tendo em vista essa primeira diferença, assim como outras que foram aos poucos sendo identificadas na historiografia da educação e nas fontes consultadas, tentou-se encontrar indícios para compor uma trajetória histórica do museu escolar. Afinal, seria um lugar dentro ou fora da escola? Seria um lugar ou um objeto? Seria um objeto ou uma série deles? Uma coleção? Seria algo definido, homogêneo, similar em todas as escolas, ou seria diversificado, heterogêneo, cambiante de acordo com as localidades?

Considerando que os objetos possuem uma trajetória, para traçar e explicar suas biografias "é necessário examiná-los em situação, nas diversas modalidades e efeitos das apropriações de que foram parte. Não se trata de recompor um cenário material, mas de entender os artefatos na interação social" (Meneses, 1998, p. 92). Neste sentido, privilegiamos a descrição dos objetos em situação.

A partir da articulação dessas possibilidades e dos indícios localizados, elaboramos seis aproximações ao termo museu escolar, que carrega consigo alguma imprecisão, razão pela qual passamos a considerá-lo polissêmico, visto que varia de sentido conforme o contexto. Assim como ocorre com toda palavra desta ordem, há necessidade, no momento de sua aplicação, de se remeter ao conteúdo e ao contexto especificado, uma espécie de adjetivação da palavra.

\section{Dos diferentes formatos de museus}

Em alguns casos a expressão museu escolar pode remeter a formatos de museus que não o representam, tais como de arte, históricos ou mesmo de escolas, como, por exemplo, o Museu da Escola de Minas Gerais ou o Museu da Escola Catarinense. Este último tipo se relaciona à temática educativa numa perspectiva muitas vezes histórica, mas não é de fato extensão ou continuidade dos museus constituídos como aparato pedagógico. Ainda que possam ter finalidades que se assemelhem a institutos de formação de professores, são fruto de um contexto bastante diverso e têm tarefas distintas.

Assim, a primeira relação de proximidade que propomos está no uso dos termos museu escolar e pedagógico ${ }^{1}$. Tomados, muitas vezes, como sinônimos, as diferenças se evidenciam numa incursão mais detida pela literatura da área, assim como no corpus documental que dá forma a escola. Importa aqui tratar justamente destas diferentes concepções embutidas nos termos sem se deter em juízos acerca dos modos de emprego da expressão.

\footnotetext{
${ }^{1}$ Vidal (2012) considera a distinção entre os dois termos uma precaução teórica fundamental.
} \begin{tabular}{|l|l|l|l|l|} 
Hist. Educ. [Online] & Porto Alegre & v. 17 & n. 41 & Set./dez. 2013
\end{tabular} p. $79-101$ 
Numa ligeira incursão por parte da literatura educacional do final do século 19 e início do século 20, pode-se distingui-los da seguinte maneira: o primeiro - escolar -, alojado dentro das instituições educativas, deveria servir a professor e a alunos para a realização de estudos pautados no concreto, isto é, agregar um conjunto de objetos para tornar a aprendizagem intuitiva. O segundo - pedagógico - caracteriza-se como um centro de formação para professores, onde seriam desenvolvidos, testados, apresentados e difundidos novos métodos, mobiliários e instrumentos didáticos.

A distinção entre estes termos pode ser encontrada num conjunto importante de textos da literatura pedagógica, como no dicionário dirigido por Buisson (1887, 1911), no editado por Monroe (1926), no texto de Frazão, que compõe as atas do Congresso de Instrução Pública (1884 apud Vidal, 1999) e no artigo de Lemos (1923)². As funções de um museu pedagógico foram descritas também por Cossío (1884, [18--?]), diretor do Museu Pedagógico Nacional da Espanha que já alertara sobre certa confusão no emprego dos termos:

Ambos contienen material de enseñanza, y el mismo material de enseñanza. De aquí la confusión que fácilmente puede hacerse y se hace con frecuencia entre unos y otros. Sin embargo, la distinción se halla claramente establecida y de un modo absoluto, mediante la nota, ya indicada, del examen crítico. Entre un Museo escolar e uno pedagógico hay la misma diferencia que entre educación y pedagogía. El material del primero ha de servir para educar; el del segundo para aprender a educar ${ }^{3}$. (Cossío, [18--?], p. 134)

Os indicativos localizados compõem um quadro explicativo do que seria um museu pedagógico, ou seja, um espaço que agregaria objetos que ensinariam os professores a educar.

Estudos historiográficos do campo educativo ${ }^{4}$ indicam que os museus escolares foram impulsionados por outra modalidade de museus, os pedagógicos. Estes conheceram seu auge nas exposições universais, que funcionaram como uma espécie de estímulo à criação de museus ocupados da temática educativa (Bastos, 2002, p. 254). Aliados a estas exposições, ocorriam congressos ${ }^{5}$ nas mais diferentes áreas, que se caracterizaram como espaços de discussão que procuravam padronizar alguns setores.

Os museus pedagógicos tinham a característica comum de funcionarem como instituições formadoras de professores. Em geral, possuíam bibliotecas anexas,

\footnotetext{
${ }^{2}$ Apresenta-se, ao final, uma extensa bibliografia do período que trata sobre museus escolares e pedagógicos.

3 "Ambos contêm material de ensino, e o mesmo material de ensino. Daí a confusão que facilmente pode fazer-se e faz-se com frequência entre uns e outros. Sem dúvida, a distinção é claramente estabelecida e de um modo absoluto, mediante a nota, já indicada, do exame crítico. Entre um Museu escolar e um pedagógico há a mesma diferença que entre educação e pedagogia. O material do primeiro tem de servir para educar; e o do segundo para aprender a educar".

4 Principalmente Felgueiras (2011), Mogarro (2010), Meneses (2003), Bastos (2002), Vidal (1999, 2006, 2009).

${ }^{5}$ A partir da exposição de Paris de 1878, passou a ser obrigatória a realização de congressos durante as feiras internacionais. Estes se tornaram mais uma coisa a ser exposta. Eram divulgados "como os principais espetáculos de ciência e progresso, mas abertos apenas para públicos selecionados". Passaram a realizar-se também exposições com temáticas específicas, aliadas ou não aos congressos. Da educação, têm-se três exemplos de eventos desta ordem, em 1880 na Bélgica, em 1883 no Brasil e em 1884 na Inglaterra (Kuhlmann Júnior, 2001, p. 88).
}

Hist. Educ. [Online] (Kuhlmann Júnior, 2001

ก. 41

Set./dez. 2013

p. $79-101$ 
produziam e distribuíam periódicos e livros voltados aos modernos métodos e materiais de ensino, a fim de instrumentalizar a prática dos professores.

Para Maria Helena Camara Bastos (2002, p. 258) a concepção de um museu pedagógico se inseriu na "representação da modernidade educacional brasileira" a partir de 1870, consequência da "participação nas exposições internacionais, do contato com publicações e de visitas a estabelecimentos estrangeiros."

A criação do primeiro museu pedagógico brasileiro data de 2 de dezembro de 1883, tendo sido chamado de Museu Escolar Nacional, situado no Rio de Janeiro. Sua concepção se relaciona com a Primeira Exposição Pedagógica, a qual legou parte dos objetos que viriam a constituir o acervo do museu. Depois de fundado, o Museu Escolar Nacional passou a funcionar no andar superior da Imprensa Nacional, sendo aberto ao público duas vezes por semana, além do dia inteiro aos domingos. Entre 1884 e 1887 promoveu exposições escolares anuais (Bastos, 2002). O fato de o primeiro museu pedagógico brasileiro chamar-se Museu Escolar de algum modo explicita a proximidade e imprecisão antes apontada.

Em 1890 fundou-se um novo museu pedagógico, intitulado Pedagogium, por meio do decreto n. 667, de 16 de agosto, durante o mandato do ministro Benjamin Constant. Este teve início, ao que tudo indica, com a biblioteca e material clássico da Associação Mantenedora do Museu Escolar, então extinta, e da Associação Promotora da Instrução. Menezes Vieira foi nomeado diretor do Pedagogium em 20 de agosto de 1890, podendo "ser considerado o seu criador e grande estimulador" (Ibid., p. 274).

Entre as atividades do Pedagogium esteve a edição de uma revista intitulada Revista Pedagogica, que

teve uma duração de seis anos, tendo iniciado sua circulação em 15/11/1890, uma data que nos sugere ser comemorativa do primeiro aniversário do novo regime republicano. O último número, pelo que consta no acervo da Biblioteca Nacional, foi publicado em 15/6/1896, embora no periódico Educação e Ensino, que se apresenta como o sucessor da Revista Pedagogica, haja a informação de que o último número tenha sido publicado em janeiro de 1897. (Gondra, 1997, p. 375)

Segundo Gondra (1997), a revista serviu como um "instrumento para fazer circular o discurso republicano a ser distribuído gratuitamente a todos os professores - públicos e particulares" (p. 378). Além desta publicação o museu ainda promoveu, entre 1891 e 1896, cursos e conferências, bem como exposições escolares anuais, com trabalhos de alunos, professores e material de ensino.

Entre os objetivos do Pedagogium esteve também a disseminação de instituições similares em outros Estados e a organização de museus escolares nas escolas brasileiras. A presença de museus nas escolas estava prevista no artigo nono do Regulamento da Instrução Primária e Secundária do Distrito Federal, aprovado pelo decreto n. 981, de 8 de novembro 1890.

Além desta iniciativa nacional, alguns Estados empenharam-se em criar seus museus pedagógicos. O Estado de Alagoas instalou seu Pedagogium em 3 de maio de 1891 e o de São Paulo criou, em 1895, o Instituto Pedagógico Paulista (Bastos, 2002). 
Além destes, Leontina Busch (1937) identificou, na legislação educacional de alguns Estados, a presença desta instituição. Por exemplo: consta no Regulamento da Instrução Pública Primária do Rio de Janeiro, de 1929, que foi criado um Museu Pedagógico. De acordo com Regulamento de 1932, o Maranhão criou seu museu pedagógico na capital. Em 1934, em exposição sobre a organização do ensino em Pernambuco, menciona-se a presença de um Museu Pedagógico Central, criado em 1931. De acordo com Busch (1937), museus escolares e pedagógicos estiveram presentes na legislação de pelo menos sete Estados brasileiros ${ }^{6}$ nas décadas de 1920 e 1930.

A segunda referência a que o termo museu escolar remete pode ser encontrada, mais facilmente, na historiografia educacional brasileira, principalmente a partir das pesquisas de Vidal $(1999,2006,2009,2012)$ sobre o Museu Escolar Brasileiro, uma versão nacionalizada do Musée Scolaire Deyrolle. Segundo esta autora, o Museu Escolar Brasileiro corresponde a uma coleção de quadros parietais produzidos na França, traduzidos, adaptados e trazidos para o Brasil, ao que tudo indica, por Menezes Vieira, que foi diretor do Pedagogium de 1890 a 1896. Estes quadros destinavam-se "ao ensino elementar das ciências naturais, principalmente, mas também da história e do que modernamente denominamos de geografia humana" (Vidal, 2009, p. 44).

Visualizam-se, a seguir, dois exemplos de quadros desta coleção. A imagem da direita é de um exemplar francês e a da esquerda um modelo traduzido e adaptado por Menezes Vieira à realidade brasileira. Ambos fazem parte acervo da Escola Normal Caetano de Campos.

Figura 1

Exemplar de quadro museu escolar da coleção francesa.

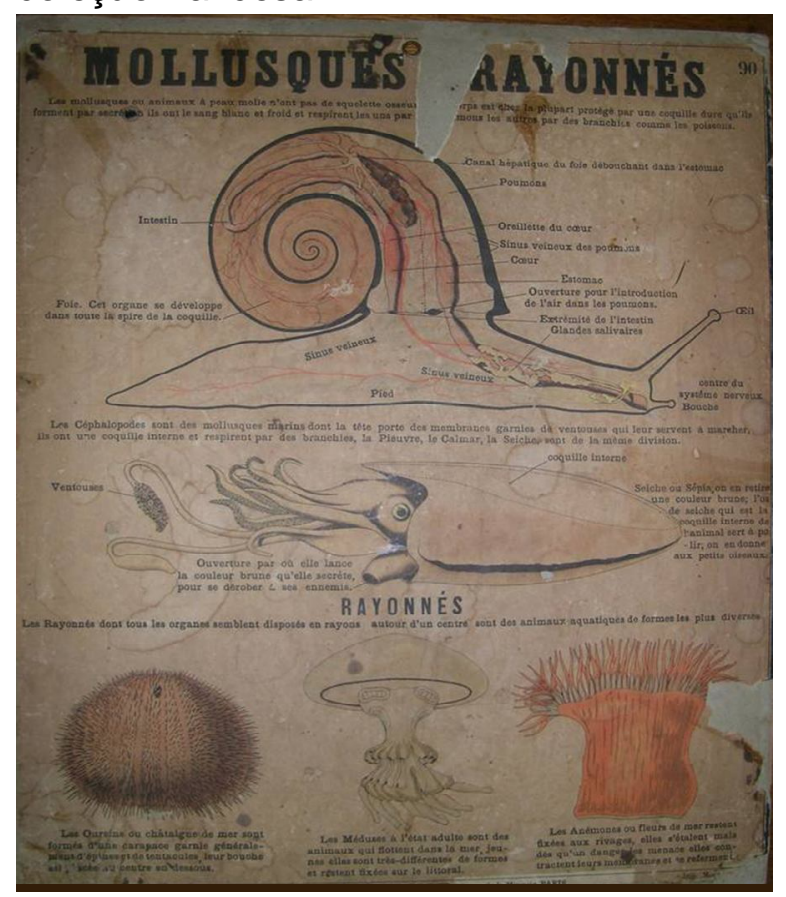

Fonte: Vidal, 2006, p. 256.
Figura 2

Exemplar de quadro museu escolar da coleção brasileira.

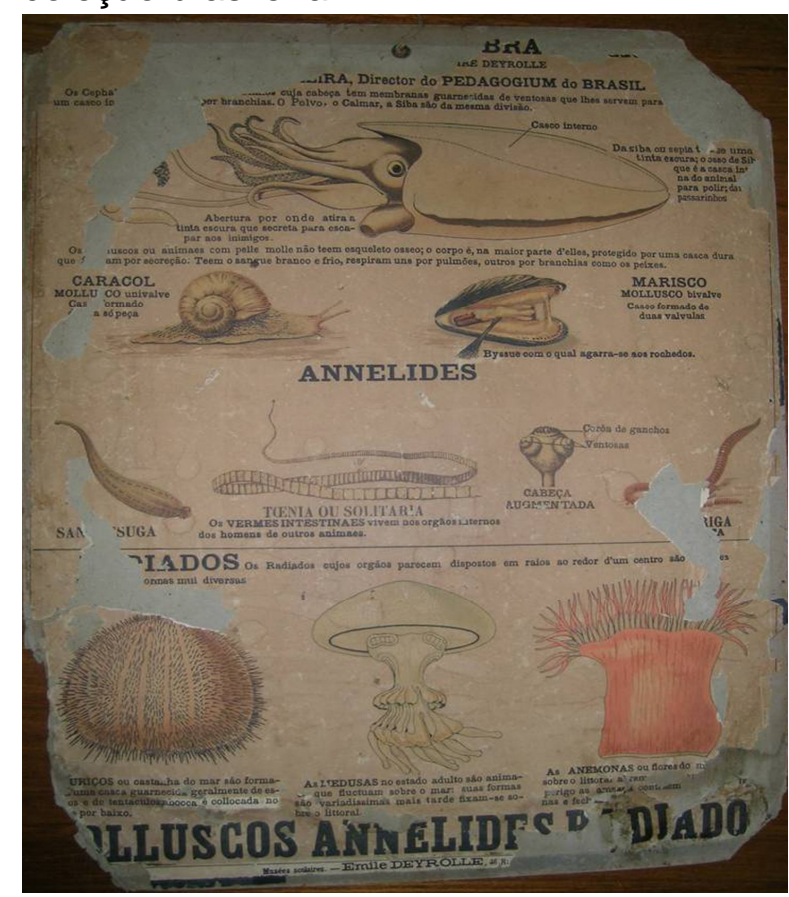

Fonte: Vidal, 2006, p. 256.

\footnotetext{
${ }^{6}$ São eles: Minas Gerais, Distrito Federal, Bahia, Sergipe, Piauí, Pernambuco e Maranhão. \begin{tabular}{|l|c|c|c|c|}
\hline Hist. Educ. [Online] & Porto Alegre & v. 17 & n. 41 & Set./dez. 2013
\end{tabular} p. $79-101$
} 
Além de quadros neste estilo, a empresa Deyrolle fabricava "peças de anatomia humana e anatomia comparada e modelos de flores e frutos" (Vidal, 2009, p. 48). Vidal (2009) observou a presença de materiais desta empresa em inventários e correspondências da Escola Normal Caetano de Campos e Escola Normal do Brás (SP). De acordo com esta autora (Ibid., p. 53), a Maison Deyrolle possuía forte tino comercial. Criada em 1831, começou a produzir as pranchas escolares em 1861 e, em 1870, o governo francês já era seu principal comprador. No Brasil, a empresa matinha um representante comercial. A data do início da tradução das pranchas para o português não é precisa. Segundo Vidal (2009, p. 48), os quadros em português e espanhol compunham o catálogo de 1897, contudo, em 1895, a Escola Normal de São Paulo já os possuía na versão traduzida, conforme se verifica em álbum fotográfico.

O entrave da língua não foi sentido apenas no caso brasileiro, o que de algum modo levou Menezes Vieira a traduzir e adaptar a coleção museu escolar. Honorio Senet (1896), inspetor das escolas da província de Buenos Aires, apontava como inconvenientes para a adoção de tal material pelas escolas: o alto preço, a pouca relação com a realidade das escolas argentinas, além da língua.

A constatação do inspetor Senet (1896) parece ter sido considerada pelos empresários franceses, que perceberam a existência de um importante mercado consumidor. Em catálogo da casa comercial francesa de 1898 encontram-se, para comercialização, pranchas editadas para a América, com versão em espanhol e português, acerca das seguintes temáticas: elementos de ciências naturais, 20 quadros; animais e vegetais úteis, 23; indústrias extrativas/tecnologia, 26; e anatomia humana, 12; num total de 81 quadros (Les Fils d'Émile Deyrolle, 1898).

Em catálogo de 1939 são oferecidos para venda "quadros muraes a cores montados em cartão". Trata-se da coleção museu escolar para lições de coisas em português. A primeira página do catálogo informa que "este Museu é apresentado em quadros de 0,59 x 0,47 com desenhos coloridos e amostras do natural" (Estabelecimentos Deyrolle, 1939, p. 1), sendo estes os componentes da coleção museu escolar completa. Além das temáticas presentes em 1898 insere-se, em 1939, uma série de quadros chamada "tipos comparados"7, e suprimem-se os quadros de tecnologia, totalizando 156 unidades e 500 amostras naturais ${ }^{8}$. Os quadros que não possuíam amostras naturais correlatas poderiam ser comercializados em papel, sem serem montados em cartão, o que significava redução no preço.

É certo que algumas escolas paulistas contaram com a presença destes materiais importados, tais como as duas escolas normais mencionadas: Escola Normal Caetano de Campos e Escola Normal do Brás. No entanto, Souza (1998, p. 230), considerando o universo do ensino primário, salienta que, "foram poucos os grupos escolares agraciados com esse moderno recurso de ensino", bem como com outros materiais importados, os quais figuravam sobretudo em escolas urbanas. Em Santa Catarina não se têm pesquisas e dados suficientes que evidenciem a compra e presença de museus importados. Há o

\footnotetext{
${ }^{7}$ Cada lâmina desta série apresenta a ilustração de uma espécie com seus semelhantes. Os exemplos vão desde mamíferos a moluscos e micróbios.

${ }^{8}$ Possuíam amostras naturais as seguintes séries: elementos de ciências naturais; os animais e os vegetais e as indústrias extrativas. Hist. Educ. [Online] 
registro, em relatório do secretário dos Negócios do Estado, enviado ao governador no final do ano de 1912, em que esse afirma:

Em cada grupo, como acima alludi, existe um pequeno, porém apropriado museu escolar, constando de especimens sobre historia natural, apparelhos de physica e de chimica, que se prestam às experiências relativas aos programmas dessas materias; quadros allegoricos sobre a nocividade do uso do alcool; quadros dos productos do paiz, de machinas de uso na lavoura e da industria pecuaria. $O$ museu para o grupo Conselheiro Mafra bem como para todos os outros do Estado, faltando apenas para o de Itajahy, cuja creação foi resolvida após a encommenda, foi adquirido em Paris, na conhecida casa E. Deyrolles \& Fils. (Santa Catarina, 1912, p. 61)

Do conteúdo deste excerto delineia-se uma imagem bastante genérica do que seria um museu, a saber, uma coleção de espécimes sobre história natural. Isto significa dizer que se poderia constituir de pequenos animais empalhados ou cartonados, no caso de borboletas, por exemplo, ou ainda de quadros temáticos, de acordo com as matérias de ensino ${ }^{9}$.

Além destes quadros importados da série museu escolar, identificamos a presença de outros, similares, porém sem serem assim nomeados. Trata-se de material produzido pelo Museu Nacional do Rio de Janeiro. A relação entre o Museu Nacional e as escolas, no que diz respeito ao fornecimento de coleções, parece ter se iniciado na década de 1890, por intermédio da ação do Pedagogium. A organização de museus escolares modelo era uma de suas atividades E, por essa razão, em 1891, Benjamin Constant, ministro da Instrução Pública, solicitou ao diretor do Museu Nacional, Ladislau Neto, "que preparasse pequenas coleções de história natural apropriadas para o ensino elementar que deveriam ser remetidas ao Pedagogium para posterior distribuição nos estabelecimentos de ensino" (Sily, 2010, p. 9).

A partir de 1916 o Regulamento do Museu Nacional fixou como uma das finalidades "estudar, ensinar e divulgar a história natural", passando a preparar regularmente espécimes e coleções em seus laboratórios, as quais seriam distribuídas entre as escolas, para o ensino de História Natural nos gabinetes e museus escolares (Sily, 2008). As temáticas dos mapas, entre 1919 e 1922, foram: antropologia, zoologia, geologia e botânica (Ibid., 2008). Na sequência, podem ser visualizados dois exemplares de quadros elementares de história natural do Brasil organizados pelo Museu Nacional do Rio de Janeiro, referentes à botânica e zoologia.

\footnotetext{
${ }^{9}$ Vale lembrar, entretanto, que o relatório apresentado ao governador cumpre a função de informar sobre as realizações de seu governo, ao mesmo tempo em que busca legitimar sua ação, destacando grandes feitos, como a compra de objetos pedagógicos internacionais.

\begin{tabular}{|l|l|l|l|l|l|}
\hline Hist. Educ. [Online] & Porto Alegre & v. 17 & n. 41 & Set./dez. 2013 & p. 79-101 \\
\hline
\end{tabular}
}


Figura 3

Quadro mural de zoologia editado pelo Museu Nacional em 1921.

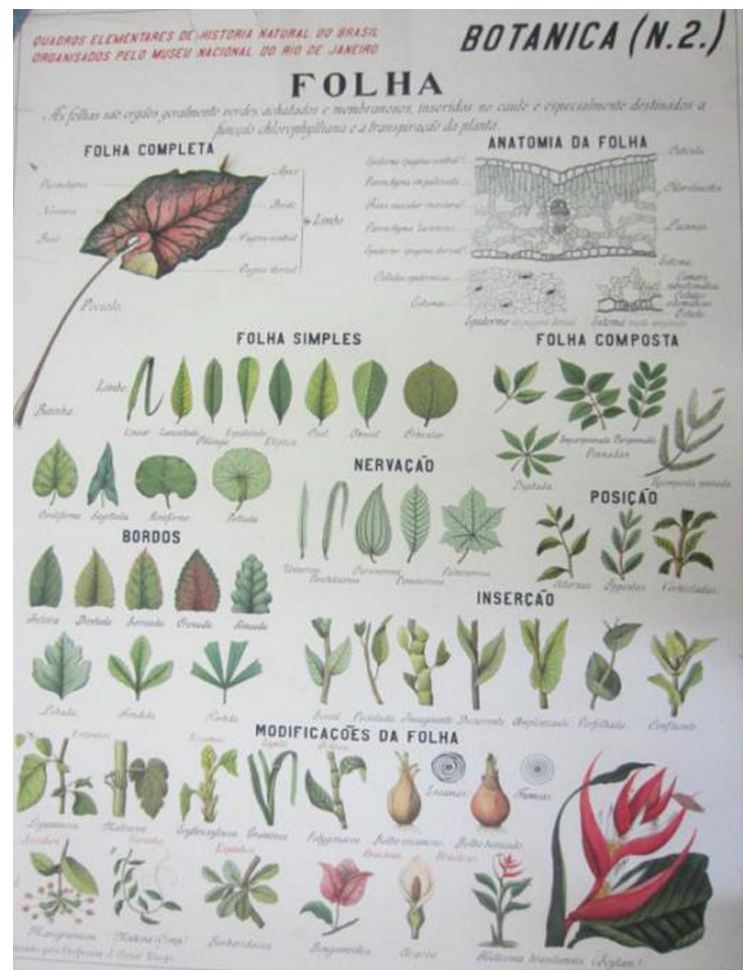

Fonte: Sily, 2012, p. 261.
Figura 4

Exemplar de quadro museu escolar da coleção brasileira.

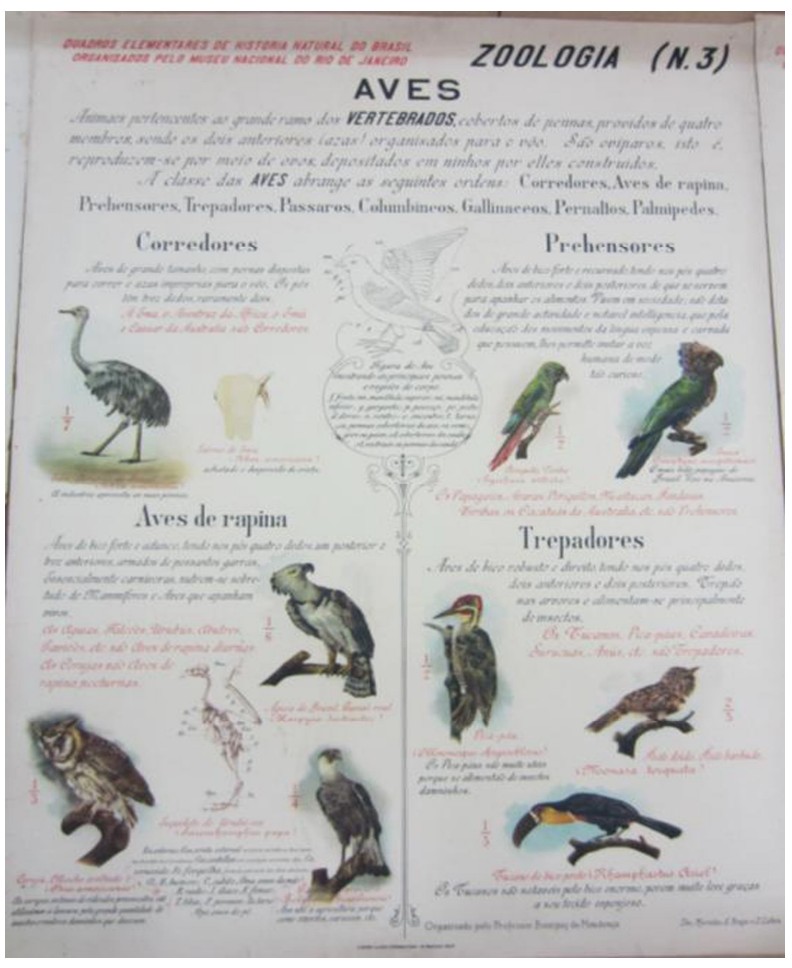

Fonte: Sily, 2012, p. 264.

Em relação à Santa Catarina há o registro de aquisição destas coleções pelo Ginásio Catarinense, instituição privada, católica e destinada ao público masculino. Contudo, esta instituição dedicava-se ao ensino médio no formato da época, não podendo ser tomada como exemplar quando se estuda o ensino primário. Segundo dados do relatório anual de 1929, o lente de História Natural, padre Maute, foi ao Rio de Janeiro "para estudar nos museus da capital federal as installações mais recentes e para augmentar o nosso museu" (Gymnasio, 1929, p. 65). Angariou objetos em diferentes instituições - Ministério da Agricultura, Instituto Biológico, Jardim Botânico - tendo conseguido, no Museu Nacional, vinte quadros murais destinados ao ensino de história natural.

Em relação às escolas públicas, temos a seguinte informação procedente do relatório do Colégio Municipal de Joinville, redigido por Orestes Guimarães, diretor do estabelecimento entre 1907 e 1909. No item material escolar, o diretor observa:

Hoje o Collegio possue uma boa colleção de mappas muraes para o ensino de schiencias naturaes (collecção, Deyrolles, abrasileirada), mappas para o ensino de geographia, sobretudo patria (Olavo Freire e Rio Branco), globo terrestre, celeste e ardosiado, apparelho Level, etc. tudo constando do inventario (anexo 37). Este material adoptado nas escolas de S. Paulo alguns feito sob a direcção do Pedagogium Brasileiro, é dos 
melhores e resiste a qualquer critica, como material didactico. (Colégio, 1909, p. 16-17)

Esta citação fornece dois elementos para pensar na circulação de objetos escolares, os quais mostram que Santa Catarina estava conectada às novidades pedagógicas. Primeiro, a menção da existência da coleção de quadros para o ensino de ciências naturais Deyrolle, na versão traduzida e adaptada, conforme anunciado, referente às pesquisas de Vidal (1999, 2006, 2009). Em segundo, a referência de que alguns destes materiais eram provenientes do Pedagogium, sem a indicação de que fossem produzidos ou apenas distribuídos por ele.

Em terceiro lugar encontra-se uma alusão ao móvel que guarda as coleções de objetos para as lições de coisas, que também aparece nomeado como museu escolar. Um móvel emblemático é o armário em madeira, com portas parcialmente envidraçadas (Teive, 2007), bastante comum no mobiliário de escolas ao longo do século 20 , o qual pode ser visualizado em diversas fotografias de sala de aula. Na organização da sala de aula ou da escola este móvel poderia assumir, conforme registros, a função de museu. Mas, por sua versatilidade, este mobiliário poderia desempenhar diferentes funções. De acordo com o Regimento Interno dos grupos escolares de 1914 (Santa Catarina, 1914a), cada classe deveria possuir "um armário de porta de vidro", cuja função seria de arrecadar o material dos alunos.

Encontra-se referência ao armário-museu no relatório do Grupo Escolar Particular Stella Maris e Curso Complementar Anexo do município de Laguna, do ano de 1947. De acordo com o inventário do mobiliário e material existente nas classes, havia na sala do $4^{\circ}$ ano um armário precedido da indicação, entre parênteses (museu), em bom estado, no valor de 300 cruzeiros (Grupo, 1947, p. 46).

A figura 5 é representativa do móvel mencionado e que será indicado por boa parte da literatura pedagógica para armazenar as coleções. Trata-se de um exemplar do acervo do Museu da Escola Catarinense, de Florianópolis. 
Figura 5

Armário em madeira com portas de vidro.

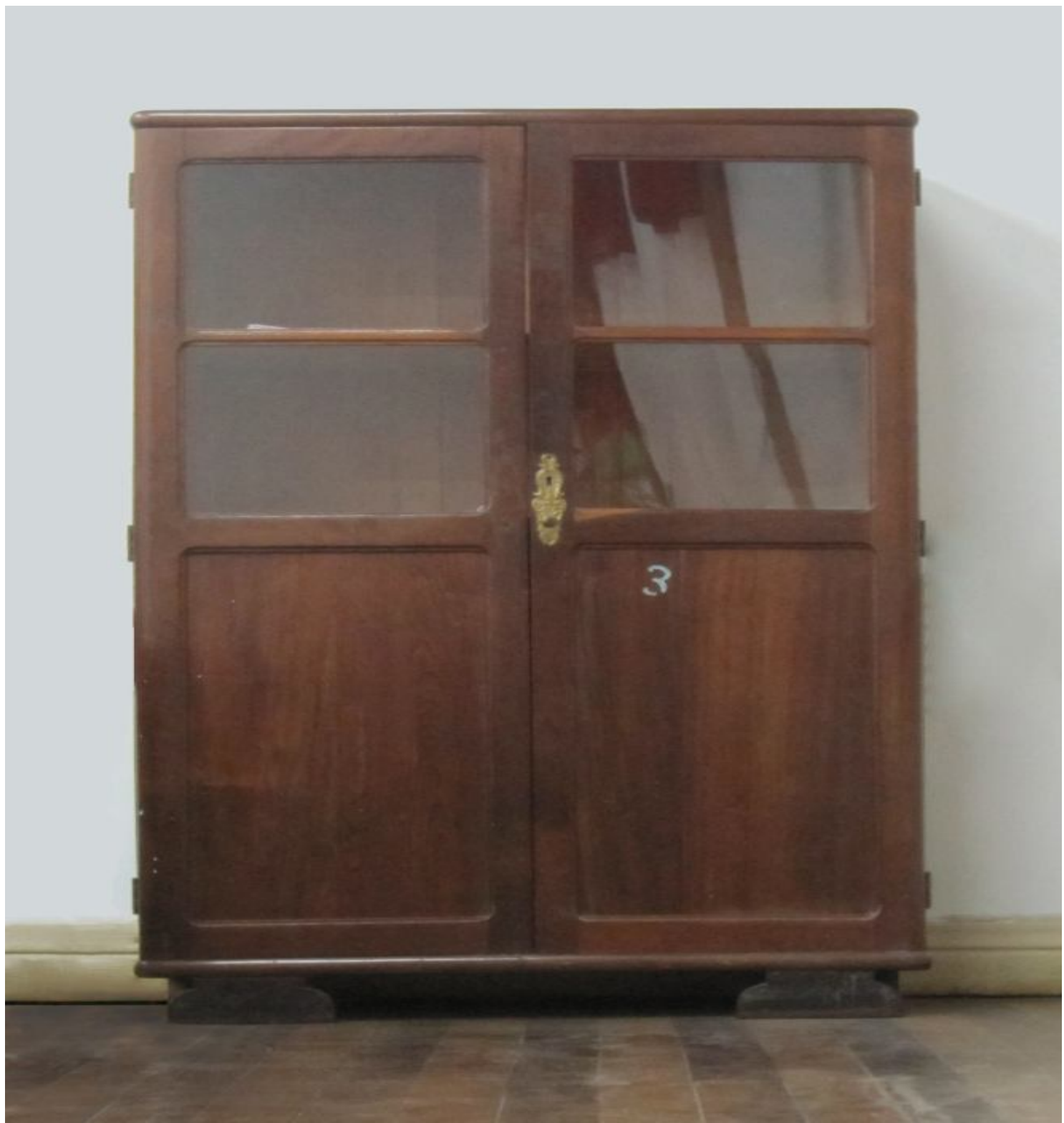

Fonte: acervo do Museu da Escola Catarinense (fotografia 22/1/2013).

O provimento das escolas com armários-museus é tratado por Martin Lawn (2005) no texto $A$ pedagogy for the public: the place of objects, observation, mechanical production and cupboards. De acordo com o autor, a partir de 1871 as ciências naturais foram adicionadas ao currículo escolar na Inglaterra, tornando-se obrigatórias em 1882. Esta obrigação ocasionou a necessidade de angariar inúmeros objetos que permitissem o ensino das lições. Como resultado do crescimento da quantidade de objetos que ingressaram nas escolas, tornou-se necessário seu armazenamento em armáriosmuseus, que deveriam ser fornecidos pelo Conselho Escolar. Desde 1888 a questão 
constava nas atas desse órgão, que recomendava que os comitês locais acatassem os pedidos dos diretores das escolas providenciando os armários.

No entendimento do autor,

as lições de coisas geraram os objetos, que geraram os gabinetes. A série de eventos que conduziu o currículo de instrução a uma pequena indústria de objetos supriu e criou os gabinetes escolares ou museus que dentro de alguns anos tornou-se prática comum em muitas escolas públicas ${ }^{10}$. (Lawn, 2005, p. 160)

Nesse processo, as escolas precisaram desenvolver uma capacidade de estocar objetos (Lawn, 2005). A solução foi encontrada no fornecimento e aquisição de armários.

Outro exemplo de mobiliário cuja função seria abrigar objetos do museu, especificamente os quadros no estilo daqueles investigados por Vidal (fig. 1 e 2), é um armário com repartições internas móveis, onde poderia ser guardado um número elevado de pranchas. Este armário permitia que as estampas do museu ficassem em frente aos olhos das crianças sem que fosse necessária uma grande superfície mural (Les Fils D'émile Deyrolle, 1898).

A figura 6 corresponde a um modelo deste armário, com 2,20m de altura, 1,24m de largura e 0,40m de profundidade. Foi extraída de um catálogo de vendas de mobiliário e material de ensino da Maison Deyrolle.

Figura 6

Armoire porte-tableaux.

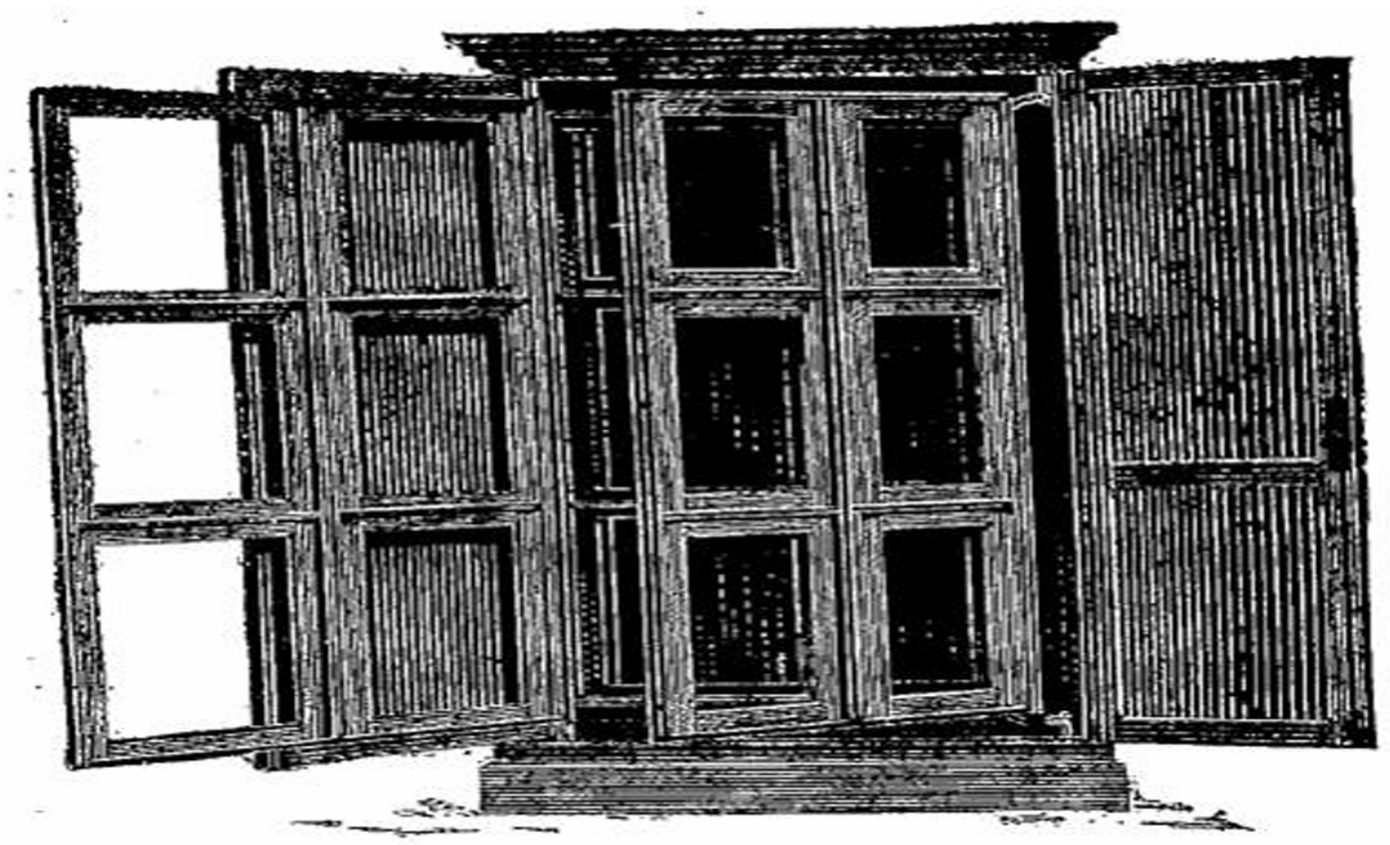

Fonte: Les Fils d'Émile Deyrolle, 1898, p. 34.

\footnotetext{
10 "Object lessons begat objects which begat cabinets. The series of events which lead from a curriculum instruction to a minor industry of object supply and the creation of school cabinets or museums took place within a few years in many state schools" (Tradução do original de David Antonio da Costa e Gustavo Rugoni de Sousa).
} 
Pode-se relacionar este formato de museu com as coleções, uma vez que as abrigaria, sendo tênue o limite que define o que é um museu: se as coleções, se o móvel ou o conjunto. De todo modo, essa diferenciação ajuda a alertar para o fato de que quando observamos na documentação que uma escola possuía museu, pode-se estar remetendo a situações bem distintas.

Além destes, a pesquisa revelou um quarto formato, a saber, o museu como recurso pedagógico instalado dentro da sala de aula. Este se vincula, especialmente, ao móvel antes descrito, pois, prescindia de um lugar onde pudesse ser instalado: armário, estante ou outro aparato que servisse como armazenador ou expositor dos objetos, como mesas, caixetas, vitrines. $O$ que interessa nesse caso é que as duas versões foram pensadas e postas em prática sem serem excludentes, como pode ser observado em relatórios escolares. Nos referimos ao Relatório do Grupo Escolar Lauro Müller e do Curso Complementar Anexo, de Florianópolis, no ano 1946. De acordo com a diretora da instituição: "cada classe possui o seu museu. Durante o ano, cada professora vai coletando o que os alunos levam. No final do ano, os objetos ou coisas mais interessantes são levados ao Museu Geral" (Grupo, 1946, p. 24).

Além de informar sobre disposições físicas, a citação fornece pistas sobre uma metodologia empregada na constituição do acervo do museu geral e indica a existência de dois tipos de museu: aquele instalado na sala de aula e outro geral, instalado em espaço específico da unidade escolar.

$\mathrm{Na}$ figura 7 podemos visualizar um exemplo de museu instalado dentro de uma sala de aula.

Figura 7

Fotografia do museu Silva Jardim localizado na Escola Estadual de Papanduva, Campo Alegre, 1946.

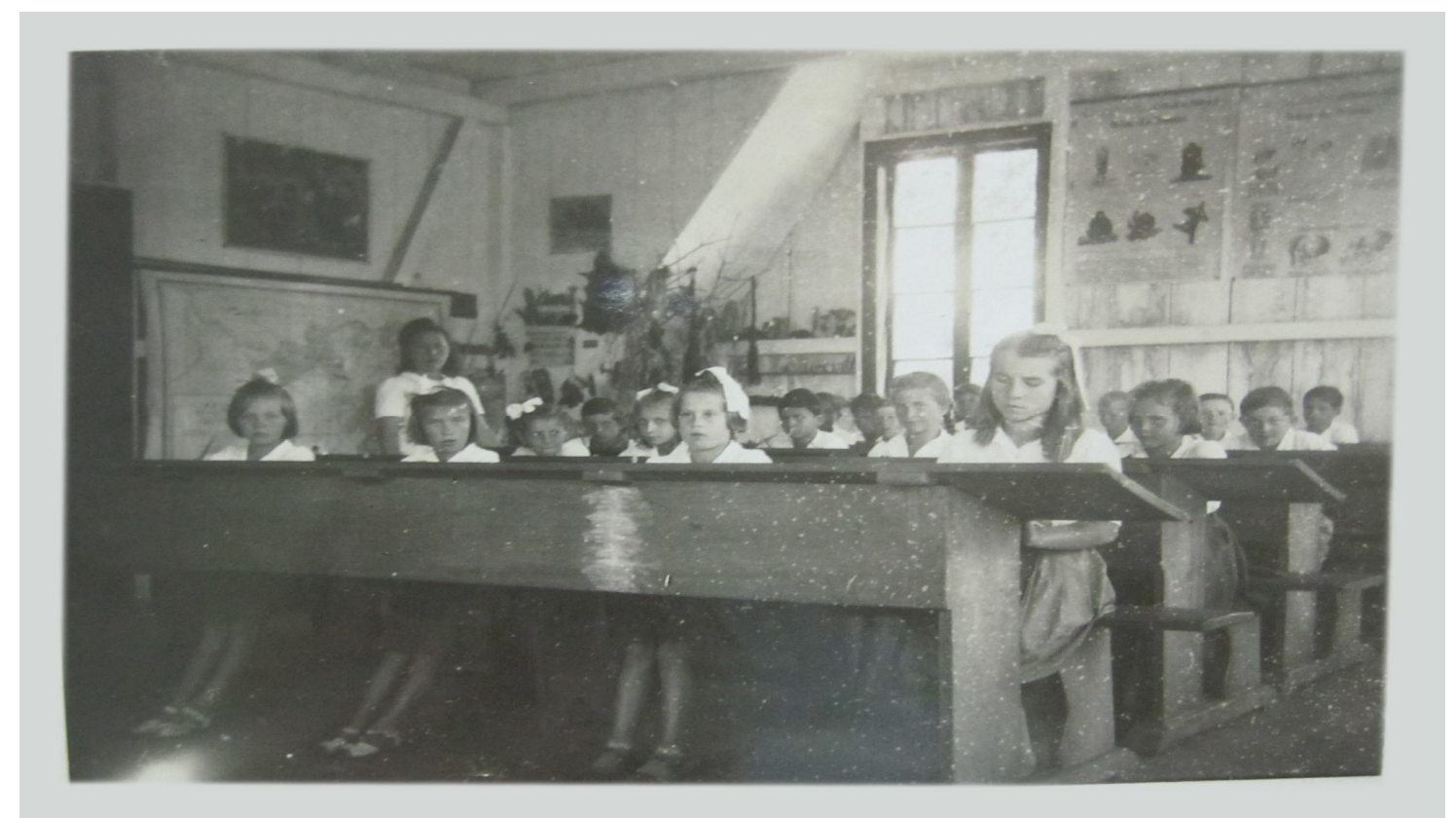

Fonte: Arquivo, 1946c, p. 424. 
Mediante um exame detalhado da fotografia pode-se ver que os objetos estão organizados sobre a madeira que compõe a parede na horizontal. O acervo contém, entre outras coisas, galhos de árvore, pele de animal afixada na parede e um suporte, ao que parece, em tecido, ao lado da pele de animal, com duas divisões. A sala possui ainda um mapa geográfico e quatro quadros com estampas; os dois do lado direito da fotografia assemelham-se aos utilizados para o ensino de ciências.

A esta quarta forma soma-se uma quinta, neste caso na condição de espaço físico ${ }^{11}$. O museu não só dava nome a coleções de quadros, objetos diversos e móveis, como poderia ocupar um espaço físico nas escolas, um pequeno gabinete onde seriam guardadas as coleções. A destinação de um espaço específico na arquitetura da escola compõe uma questão instigante, visto tratar-se, à primeira vista, da incorporação de uma máxima pedagógica - a necessidade de instaurar processos de ensino mais concretos -, criando condições materiais para a sua realização, em detrimento de outras atividades que poderiam ser exercidas dentro do espaço escolar.

A descrição de museus nas salas de aula e em um gabinete específico parece ser uma peculiaridade brasileira (Backheuser, 1934; Busch, 1937). Backheuser sugere que 0 museu da escola não esteja

constantemente franqueado aos alunos, o que o tornaria em breve objeto de menor curiosidade, mas sempre que nele haja sido feita qualquer modificação ou melhoramento, a classe deverá ser disso informada, para que se desperte o desejo de nova visita, ensejo de novas observações. (Backheuser, 1934, p. 298)

Vemos aqui uma espécie de transição entre um aparato pedagógico, que deveria oferecer a alunos e professores a possibilidade de contato direto com materiais de ensino, para uma concepção mais de espaço que guarda coisas a serem contempladas.

No tocante aos primeiros grupos escolares catarinenses previu-se, na sua construção, a destinação de um gabinete para o museu. $O$ regimento em vigor a partir de 1914 determinava que os grupos escolares tivessem oito classes. De modo similar ao de 1911, as classes seriam separadas em seção masculina e feminina e a dimensão das salas deveria obedecer ao mínimo de $9 \mathrm{~m} \times 7 \mathrm{~m} \times 5 \mathrm{~m}$. Além destes compartimentos o regimento estabelece que cada grupo deveria possuir: um gabinete para o museu escolar; um gabinete para o diretor; um cômodo para a portaria; um galpão de abrigo para cada seção, com privadas, lavatórios e mictórios na seção masculina; pátios arborizados para os recreios (Santa Catarina, 1914a, p. 8). Curiosamente a presença da biblioteca era facultativa, podendo o grupo possuí-la ou não; no caso de a possuir, o acervo seria emprestado tanto aos professores, quanto aos estudantes do estabelecimento.

Dos seis primeiros grupos apenas no Vidal Ramos, no município de Lages, existia um gabinete de física e química e um gabinete do museu escolar, devido a maior amplitude do prédio. Nos cinco demais os aparelhos de física e química foram dispostos no mesmo espaço reservado ao museu (Santa Catarina, 1914b, p. 153).

Por dividirem o ambiente com o laboratório de física e química, e por seu tamanho reduzido - no GE Lauro Müller as dimensões do espaço destinado ao museu eram 4,00m

\footnotetext{
${ }^{11}$ Como referência para aprofundamento da questão sobre a distribuição dos espaços físicos no ambiente escolar e seus possíveis significados, ver Viñao Frago (2005).

\begin{tabular}{|l|l|l|l|l|l|} 
Hist. Educ. [Online] & Porto Alegre & v. 17 & n. 41 & Set./dez. 2013 & p. 79-101
\end{tabular}
}


x 3,50m x 4,40m (Grupo, 1946) -, é provável que o local não fosse utilizado para ministrar aulas práticas. Aliás, conforme registros, nos grupos escolares era função do porteiro a retirada dos materiais do museu e de outras dependências, o que indicia o uso deste como lugar de guarda ou depósito, distanciando-se da função de laboratório. Conforme o artigo 12 do Regimento Interno dos Grupos Escolares (1914), o material de uso comum ficaria no gabinete do diretor, na portaria e no gabinete do museu. $\mathrm{O}$ quarto parágrafo informa que "o professor deverá requisitar do porteiro, os quadros ou apparelhos de que necessitar para o ensino na sua classe e recommendar ao mesmo para que diariamente, terminadas as aulas, recolha taes apparelhos aos depositos competentes" (Santa Catarina, 1914a, p. 9).

Até os anos de 1930 não há menção a existência de museus, em escolas isoladas, seja como coleções ou como espaço físico. Isso irá mudar quando, no início da década de 1940, ao menos na legislação catarinense, o museu torna-se uma associação auxiliar da escola, o que constitui o sexto formato por nós identificado. Em 1944 o Departamento de Educação de Santa Catarina regulamentou a existência das seguintes associações: liga pró-língua nacional; biblioteca; jornal escolar; clube agrícola; círculo de pais e professores; museus escolares; centros de interesse; liga de bondade; clube de leitura e pelotão de saúde (Santa Catarina, 1944). Contudo, em anos anteriores, também eram consideradas a caixa escolar, a cooperativa escolar de consumo, o orfeão e a sopa escolar (Santa Catarina, 1942a, 1942b, 1943b). Todas teriam funcionamento gradativo. O orfeão e o clube agrícola seriam instalados quando possível (Santa Catarina, 1943a). Entretanto, muito antes de serem assim caracterizadas, algumas destas instituições já faziam parte do cotidiano das escolas, caso do museu e da biblioteca, desde a década de 1910, da caixa escolar (1916) e dos clubes agrícolas, introduzidos a partir de 1935, conforme Fiori (2002).

As associações tinham funções e objetivos específicos mas, de modo geral, deveriam promover o associativismo estudantil, preparar os estudantes para viver em sociedade, promover, no interior das escolas, a criação de sociedades em miniatura, as quais desenvolveriam qualidades como ordem, iniciativa e liderança (Santa Catarina, 1941).

Trata-se basicamente de organizações estudantis, formadas por alunos de diferentes séries, coordenadas por um professor responsável, cada uma com tarefas determinadas de acordo com seu propósito. Funcionavam como uma espécie de organismo auxiliar da atividade de ensino ou de socialização, moralização e civilização dos estudantes, bem como de aproximação da escola com a família. As associações eram organizadas no início de cada ano letivo, quando um professor era designado para sua coordenação, em geral na primeira ou segunda reunião pedagógica. A partir disso, elegia-se uma diretoria composta por alunos que deveriam cumprir algumas tarefas, as quais deveriam ser registradas em atas mensais e relatórios anuais.

$\mathrm{Na}$ condição de associação, o museu deveria cumprir uma série de expedientes burocráticos, como a eleição de diretoria, registro das reuniões em atas e escrita de relatórios anuais das atividades desenvolvidas, relação dos objetos adquiridos, etc. Esta demanda, criada na década de 1940, fez com que o número de registros relativos a esse período, depositados no Arquivo Público do Estado de Santa Catarina (Apesc) e que informam sobre museus, seja bastante superior ao das décadas anteriores. O status \begin{tabular}{|l|l|l|l|l|r|}
\hline Hist. Educ. [Online] & Porto Alegre & v. 17 & n. 41 & Set./dez. 2013 & p. 79-101 \\
\hline
\end{tabular} 
associativo leva a alguns questionamentos: tratou-se, afinal, de uma renovação das funções e perfil dos museus? Ou, mudou apenas o estatuto que os nomeava dentro das escolas?

O decreto n. 2.991, de 1944, baixou as instruções para o funcionamento das associações, sendo o primeiro documento completo a especificar a função de cada uma, embora a existência destas date já do final dos anos 1930. Este documento considerava que "tudo quanto for capaz de oferecer motivo para estudo deverá fazer parte do museu" (Santa Catarina, 1944, p.142).

Nessa nova condição, o museu deveria possuir as seguintes coleções:

a) coleção de madeiras da região e de fora dela: classificadas de acordo com o nome, habitat e serventia de cada espécie;

b) coleção de minerais existentes na localidade e, se possível, no Estado e Brasil: a classificação deveria ser feita por alguém que conhecesse as características dos minerais. Conforme o decreto, as amostras pequenas e de grande valor "devem ser colocados em caixetas cobertas com vidro ou papel transparente, o que evitaria o contacto das mãos e conseqüente decomposição" (Santa Catarina, 1944, p. 142). As coleções seriam organizadas em estantes, sobre cartolina que contenha os dados correspondentes a elas;

c) coleção de produtos agrícolas: reunidos por famílias e por município produtor, seriam distribuídos em pequenos vidros com legenda informando sobre sua utilidade prática: o milho fornece: farinha, fubá, quirera, cangica, pipoca, etc. Também fariam parte dessa coleção os produtos destinados ao tecido, como linho, algodão, rama, pita, gravatá, tecum, juta, graxima, caroá, etc.;

d) coleção industrial do município: se possível cada tipo de indústria teria uma representação em miniatura: "As fábricas de bebidas poderão ser representadas pelos rótulos de seus diversos produtos" (Santa Catarina, 1944, p. 143);

e) coleção histórica: composta por objetos utilizados pelos índios e outros, com a informação da procedência, a fim de "realizar comparações com os objetos da vida atual, pois existem objetos históricos que, dispersos, não têm valor, mas, reunidos, podem reconstituir "episódios originais da nossa vida" (Santa Catarina, 1944, p. 143).

Considerando o corpus documental até aqui acessado, este é o primeiro momento em que a composição de um museu fica clara para o caso catarinense. O texto detalha do que se trata e como organizá-lo, o que poderia ser feito por meio de excursões ou correspondência com outras escolas. Contudo, não consideramos este conteúdo completamente original, pois replica certo consenso já existente entre os pedagogos no final do século 19, que consideravam o museu não apenas como ferramenta de estudo das ciências naturais, embora a afinidade com este saber fosse mais evidente; a necessidade dele se adequar à realidade da região onde a escola estaria inserida; a importância de não ser demasiado especializado ou classificado rigorosamente a partir do 
repertório de especialistas; a necessidade de sua constituição se articular ao programa de ensino, não sendo casual nem aleatória ${ }^{12}$.

Mais ou menos ao mesmo tempo em que se discutia em Santa Catarina acerca das associações auxiliares, Backheuser (1934) e Busch (1937) buscavam afirmar as novas características dos museus. Para eles,

o museu escolar na escola nova não pode ser identico ao da escola tradicional. Nesta, estando a escola preocupada essencialmente com o ensinar, o museu que interessava era apenas o museu de historia natural, com algumas pedras, alguns vegetais, alguns animais. (Backheuser, 1934, p. 295)

Além do mais, esse novo museu,

perdendo aquelle caracter estatico, que Ihe dava a escola tradicional, de collecções de quadros Deyrolle, de historia natural e de outros, de animaes empalhados, etc., não raro representando ou concretizando muita cousa estranha ao programa escolar, o museu da escola evoluida, senão renovada, deve ser dynamico e seu conteudo deve reflectir o proprio programma de ensino. Constituido, a pouco e pouco, em funcção do desenvolvimento mesmo do programma de ensino de cada matéria, pelo esforço conjugado dos alunos e do mestre, este guiando e aquelles multiplicando suas atividades de pesquisa de cousas do meio e à distancia. (Busch, 1937, p. 36)

Para Houssaye (2007), essa polarização entre o novo e o velho se explica pela necessidade de demarcar uma diferença, pois esta é que dá a uma nova pedagogia o status de nova. O esquecimento das ideias anteriores é fundamental nesse processo, pois, caso contrário, o novo pensamento se tornaria herdeiro do anterior e não criador, o que supõe mentir sobre suas origens, na perspectiva do autor. Apesar desse esforço em negar as origens notamos, nos impressos e documentos analisados, certa circularidade de pensamento.

Por outro lado, por meio do mapeamento de estatísticas educacionais do Instituto Brasileiro de Geografia e Estatística percebemos que, em nível de Brasil, até 1937, os museus eram considerados como parte da estrutura material da escola. Nos registros, o IBGE os considera como aparelhamento escolar, ao lado da biblioteca, dos aparelhos de projeção fixa ou animada e dos laboratórios, enquanto apresenta em separado as estatísticas referentes às instituições escolares, outra forma de designar as associações auxiliares $^{13}$. Mas se até 1937 o museu é considerado uma parte material da escola, pelo menos a partir de 1938 ele é considerado claramente uma instituição escolar para o Departamento de Educação de Santa Catarina (Santa Catarina, 1942b; 1943b). Esta alteração de formato responderá por uma ampliação no número de associações. Enquanto em 1937 haviam 46 museus em escolas primárias catarinenses, incluindo as esferas federal, estadual, municipal e particular, em 1938 serão 71 e em 1942 serão 205.

\footnotetext{
12 Tais princípios encontram-se, ainda que de modo disperso, nas seguintes referências: Amor (1935), Backheuser (1934), Bannwarth (1925), Busch (1937), Ferreira (1914), Figueiredo (1924), Frazão (1884), Senet (1896).

${ }^{13}$ Dados disponíveis em: <http://www.ibge.gov.br/seculo20/default.shtm>.

\begin{tabular}{|l|l|l|l|l|l|}
\hline Hist. Educ. [Online] & Porto Alegre & v. 17 & n. 41 & Set./dez. 2013 & p. 79-101 \\
\hline
\end{tabular}
}


Uma das mudanças perceptíveis em relação a essa alteração no status do museu em Santa Catarina foi a sua progressiva expansão pelas escolas de todo o território estadual, incluindo as escolas isoladas e reunidas. Da documentação localizada no Apesc, entre os anos 1944 e 1951, identificamos a presença de museus em 319 escolas. Este universo deu origem a uma massa documental composta por 1.148 atas e relatórios, que apresentam informação acerca do cotidiano da associação, incluindo a relação do acervo existente, as formas utilizadas para angariar objetos, as atividades desenvolvidas, desde limpeza, classificação, descarte, exposições e seu uso em aulas de noções comuns.

\section{Considerações finais}

Neste artigo foram apresentados possíveis sentidos atribuídos ao termo museu escolar em parte do século 19 e, sobretudo, no século 20. Seis acepções foram elencadas, demonstrando o que se nomeou por polissemia do termo e a impossibilidade de aprisioná-lo em uma definição única. Isto evidencia a necessidade de se compreender um objeto, artefato ou utensílio do passado, inserido no contexto que o produziu, seja retórica ou materialmente.

Ao se falar de museu escolar ou museu pedagógico no final do século 19, na metade do século 20 e agora no século 21, no caso dos museus da escola, não se está falando da mesma coisa, embora seja possível localizar afinidades. Dizer que determinada escola possuía museu escolar não é suficiente para compreender o sentido que a expressão tinha num determinado tempo e lugar, fazendo-se necessário interrogar sobre o tipo ou modalidade de museu pensado ou instituído e a finalidade.

O museu não só comporta vários sentidos, materializando-se em diferentes formatos, como recebe distintas denominações, sendo chamado, por exemplo, de museu didático (Busch, 1937). Além dessas distinções, conceituar e definir o que ele foi a partir de um sentido, seja museu gabinete ou associação auxiliar da escola, não é simples, uma vez que verificamos que as escolas encontraram um jeito único de montar o próprio museu, privilegiando determinadas peças em detrimento de outras, utilizando-o para funções distintas. Assim, apresentar uma explicação clara e objetiva do que foi um museu seria incorrer no risco de uma generalização.

\section{Referências}

AMOR, Manuel Antunes. Museus escolares. Revista Escolar, v. 15, n. 9, 1935, p. 465472.

ARQUIVO PÚBLICO DO ESTADO DE SANTA CATARINA. Relatórios das escolas para Departamento de Educação. 1946c.

BACKHEUSER, Everardo. Técnica da pedagogia moderna: teoria e prática da Escola Nova. Rio de Janeiro: Civilização Brasileira, 1934.

BAGNAUX, Joseph-Charles Boyetet de. Conférence faite à la Sorbonne aux Instituteurs des Départements délégués à l'Exposition universelle de 1878 sur le mobilier de classe, le matériel d'enseignement et les musées scolaires. Paris: Librairie Charles Delagrave, 1879. 
BANNWARTH, E. Le livre auxiliare des maîtres pour l'organisation des musées scolaires: principies, èlèments, classification, usages. Paris: Librairie Classique Fernand Nathan, 1925.

BASTOS, Maria Helena Camara. Pedagogium: templo da modernidade educacional republicana brasileira (1890-1919). In: BASTOS, Maria Helena Camara. Pro Patria Laboremus: Joaquim José de Menezes Vieira (1848-1897). Bragança Paulista: Edusf, 2002, p. 251-350.

BROUARD, Eugène; DEFODON, Charles. VII - Des musées scolaires. In: BROUARD, Eugène; DEFODON, Charles. Inspection des écoles primaires. Paris: Librairie Hachette et $\mathrm{C}^{\mathrm{ie}}, 1887$, p. 383-386.

BUISSON, Ferdinand. Musées scolaires. In: BUISSON, Ferdinand (directeur). Dictionnaire de pédagogie et d'Instruction primaire. Paris: Librairíe Hachette, 1887, p. 1991-1993.

BUISSON, Ferdinand. Musées scolaires. In: BUISSON, Ferdinand (directeur). Nouveau dictionnaire de pédagogie et d'instruction primaire. Paris: Librairie Hachette et $C^{\text {ie }}$, v. 2, 1911, p. 1376-1378.

BUSCH, Leontina Silva. Organização de museus escolares: uma experiência realizada pela autora durante o curso de pratica de ensino, dado às professorandas de 1936. São Paulo: Empreza Ed. Brasileira, 1937. Acervo Histórico do Livro Escolar - AHLE - Biblioteca Monteiro Lobato - Secretaria Municipal de Cultura de São Paulo.

CAMPAGNE, Émile Mathieu. Museus escolares. In: CAMPAGNE, Émile Mathieu. Diccionario universal de educação e ensino. Porto: Lugan \& Genelioux, Sucessores, 1886, p. 886-887.

COLÉGIO MUNICIPAL DE JOINVILLE. Relatório do colégio de 1907 a 1909, apresentado ao Superintendente Municipal pelo diretor em comissão, Orestes de Oliveira Guimarães. 20 abr., 1909. Acervo: Arquivo Histórico de Joinville.

COSsíO, Manuel Bartolomé. El museo pedagógico de Madrid. In: El maestro, la escuela y el material de enseñanza y otros escritos. Edición y estudio introductorio de Eugenio Otera Urtaza. Madrid: Biblioteca Nueva, 2007. p. 122-131. [Informe leído en la Conferencia internacional de educación celebrada en Londres. Boletín de la Institución Libre de Enseñanza, VIII, p. 313-317, 1884.]

COSsíO, Manuel Bartolomé. Que és un museo pedagógico. Dos textos inéditos. In: El maestro, la escuela y el material de enseñanza y otros escritos. Edición y estudio introductorio de Eugenio Otera Urtaza. Madrid: Biblioteca Nueva, 2007. p. 133-137. [Archivo de la Fundación Francisco Giner de los Ríos, depositado en la Biblioteca de la Real Academia de la Historia, [18--?].]

CROCE, Eduardo Della; CAMPOAMOR, Deolindo M. Los museos escolares: el museo escolar actual. In: CROCE, Eduardo Della. Creación del museo escolar de La Plata. La Plata, 1908, p. 13-30.

DORANGEON, C. Leçon de choses d'aprés le musée industriel scolaire de C. Dorangeon. Paris: Librairie Ch. Delagrave, 1884. Acervo digital: Bibliothèque Nationale de France, Gallica Bibliothèque Numérique.

ESTABELECIMENTOS DEYROLLE. [Catálogo de quadros muraes, modelos anatomicos, mineralogia, tecnologia, aparelhos de física, de projeção e preparações microscopicas]. Fornecedores dos principaes estabelecimentos de ensino do mundo. mar. Paris: Évreux, Imprimerie Hérissey, 1939. 
FALARZ, Nicheporo Modesto. Organização dos museus escolares: sua importância. In: COSTA, Maria José Franco Ferreira da; SHENA, Denilson Roberto; SCHMIDT, Maria Auxiliadora (org.). CONFERÊNCIA NACIONAL DE EDUCAÇÃO, 1, 1927, Curitiba. Anais ... Brasília: MEC; Sedia/Inep; Ipardes, 1997, p. 116-120.

FELGUEIRAS, Margarida Louro. Herança educativa e museus: reflexões em torno das práticas de investigação, preservação e divulgação histórica. Revista Brasileira de História da Educação, São Paulo, v. 11, n. 1, 2011, p. 67-92.

FERREIRA, Fernando Palyart Pinto. Museus escolares. In: Separata do Anuário da Casa Pia de Lisboa de 1913-1914. Lisboa: Tipografia da Casa Portuguesa, 1914, p. 3-12.

FIGUEIREDO, Fernando Pais de. Ensino intuitivo: museu escolares. Revista Escolar, v. 4, n. 10, 1924, p. 447-454.

FIORI, Neide Almeida. Clube agrícola em Santa Catarina: ruralismo e nacionalismo na escola. Perspectiva, Florianópolis, v. 20, 2002, p. 231-260.

GONDRA, José Gonçalves. O veículo de circulação da pedagogia oficial da República: a revista pedagogica. Revista Brasileira de Estudos Pedagógicos, Brasília, v. 78, n. 188/189/190, 1997, p. 374-395.

GRUPO ESCOLAR LAURO MÜLLER E CURSO COMPLEMENTAR ANEXO. Relatório das atividades da escola no ano de 1946. Florianópolis. Diretora: Maria da Glória Mattos. Enviado ao Departamento de Educação do estado de Santa Catarina, 1946. Acervo: Museu da Escola Catarinense.

GRUPO ESCOLAR PARTICULAR STELLA MARIS E CURSO COMPLEMENTAR ANEXO. Relatório das atividades da escola no ano de 1947. Laguna. 1947. [Este documento compõe o acervo do Apesc, encontra-se num volume de atas de exames classificadas como Quadro Geral de Exames, 1948.]

GYMNASIO CHATARINENSE. Relatorio publicado no fim do anno lectivo de 1929. Florianópolis: [s.n.], 1929. Acervo: Acervo Documental do Colégio Catarinense.

HOUSSAYE, Jean. Pedagogias: importação-exportação. In: MIGNOT, Ana Chrystina Venancio; GONDRA, José Gonçalvez (org.). Viagens pedagógicas. São Paulo: Cortez, 2007, p. 294-314.

INSTITUTO BRASILEIRO DE GEOGRAFIA E ESTATÍSTICA. Série estatísticas do século 20. Disponível em: <http://www.ibge.gov.br/seculo20/default.shtm>. Acesso em: 28 maio, 2012.

KUHLMANN JÚNIOR, Moysés. As grandes festas didáticas: a educação brasileira e as exposições internacionais (1862-1922). Bragança Paulista: Edusf, 2001.

LAWN, Martin. A pedagogy for the public: the place of objects, observation, mechanical production and cupboards. In: LAWN, Martin; GROSVENOR, lan. Materialities of schooling: design, technology, objects, routines. United Kingdom: Symposium Books, 2005, p. 145-162.

LEMOS, Álvaro Viana de. Centro de cultura para professores: bibliotecas e museus. In: Revista Escolar, v. 3, n. 4, 1923, p. 97-105.

LES FILS D'ÉMILE DEYROLLE. Fabrique de mobilier et de matériel scolaires pour les enseignements maternel, primaire, secondaire et supérieur. Paris: Les fils d'Émile Deyrolle, 1898. Acervo digital: Bibliothèque Nationale de France - Gallica Bibliothèque Numérique. 
MENESES, Maria de Fátima de Faria Pinto de. Museus e ensino: uma análise histórica sobre os museus pedagógicos e escolares em Portugal (1836-1933). Lisboa: UNL, 2003. 287f. Dissertação (mestrado em Educação). Universidade Nova de Lisboa, Mestrado em Museologia e Patrimônio.

MENESES, Ulpiano Toledo Bezerra de. Memória e cultura material: documentos pessoais no espaço público. Estudos Históricos, Rio de Janeiro, v. 11, n. 21, 1998, p. 89-103.

MOGARRO, Maria João. Cultura material e modernização pedagógica em Portugal (séculos 19-20). Educatio Siglo 21, v. 28 n. 2, 2010, p. 89-114. Disponível em: <http://revistas.um.es/educatio/article/viewFile/111981/106301>. Acesso em: 19 maio, 2012.

MONROE, Paul. Museums educational \& museums school. In: MONROE, Paul. $A$ cyclopedia of education. New York: The Macmillan Company, v. 4, 1926. p. 336-341.

PELLISSON, Maurice. Musées pedagogiques. In: BUISSON, Ferdinand (directeur). Nouveau dictionnaire de pédagogie et d'instruction primaire. Paris: Librairie Hachette et $\mathrm{C}^{\mathrm{ie}}, 1911$.

REXACH, Mariano. El museo escolar: la escuela moderna. Revista Pedagógica y Administrativa de Primera Enseñanza. Madrid: Gros y Compañía, 1926, p. 360-364.

RIO DE JANEIRO. Decreto n. 981 de 8 de novembro de 1890. Approva o regulamento da instrucção primaria e secundaria do Districto Federal. 1890b. Disponível em: <http://www.histedbr.fae.unicamp.br/navegando/fontes_escritas/4_1a_Republica/decreto \%20981-1890\%20reforma\%20benjamin\%20constant.htm>. Acesso em: 31 out. 2011.

SANTA CATARINA. Decreto n. 2.991 de 28 de abril de 1944. Estabelece instruções para as associações auxiliares da escola nos estabelecimentos de ensino estaduais, municipais e particulares. Circular n. 42, 10 maio 1944. In: Circulares 1942/1944, 1944, p. 122-151. Acervo: Apesc.

SANTA CATARINA. Departamento da Educação. Circular n. 32, 2 abr. 1943. Assunto: Escrituração Escolar. Associações Auxiliares da Escola. Reuniões Pedagógicas. In: Circulares 1943-1944. Florianópolis: Imprensa Oficial do Estado, 1943a, p. 18. Acervo: Apesc.

SANTA CATARINA. Departamento de Educação. Circular n. 5, 6 jan. 1941. Assunto: sobre associações auxiliares da escola. In: Circulares 1930-1941. Florianópolis: Imprensa Oficial do Estado, 1941, p. 70-71. Acervo: Apesc.

SANTA CATARINA. Departamento de Educação. Circular n. 94, 21 out. 1942. Assunto: Associações auxiliares da escola - questionário. In: Circulares 1942. Florianópolis: Imprensa Oficial do Estado, 1942a, p. 66-67. Acervo: Apesc.

SANTA CATARINA. Regimento Interno dos grupos escolares do estado de Santa Catarina. Decreto n. 795, 2 maio 1914. Joinville: Typographia Boehm, 1914a. Acervo: Apesc.

SANTA CATARINA. Relatório apresentado ao Exmo. Sr. Cel. Vidal José de Oliveira Ramos, Governador do Estado, por Gustavo Lebon Regis, Secretário Geral em maio de 1914. Florianópolis: Typ. da Livraria Central, 1914b. Acervo: IHGSC.

SANTA CATARINA. Relatório apresentado em outubro de 1942 ao Exmo. Sr. Presidente da República, pelo Dr. Nereu Ramos, Interventor Federal do Estado de Santa Catarina, referente ao exercício de 1941. Florianópolis: Imprensa Oficial do Estado, 1942b. Acervo: Biblioteca Pública do Estado de Santa Catarina. 
SANTA CATARINA. Relatório apresentado em outubro de 1943 ao Exmo. Sr. Presidente da República, pelo Dr. Nereu Ramos, Interventor Federal do Estado de Santa Catarina, referente ao exercício de 1942. Florianópolis: Imprensa Oficial do Estado, 1943b. Acervo: Biblioteca Pública do Estado de Santa Catarina.

SANTA CATARINA. Secretaria Geral dos Negócios do Estado de Santa Catarina. Relatório apresentado ao Exm. Sr. Coronel Vidal José de Oliveira Ramos, Governador do Estado, pelo Tenente-Cnel. Caetano Vieira da Costa, Secretário Geral em 31 de maio de 1912. Florianópolis: Gab. Typ. D’O DIA, 1912.

SENET, Honorio J. Museos escolares: como se pueden formar. La Plata: Talleres-Solá, Sesé y Cia, 1896, p. 3-30.

SILY, Paulo Rogério Marques. Casa de ciência, casa de educação: ações educativas do Museu Nacional (1818-1935). Rio de Janeiro: Uerj, 2012. Tese (doutorado em Educação). 399f. Universidade do Estado do Rio de Janeiro, Faculdade de Educação.

SILY, Paulo Rogério Marques. Coleções didáticas do Museu Nacional do Rio de Janeiro: produção e circulação na primeira metade do século 20. CONGRESSO LUSO BRASILEIRO DE HISTÓRIA DA EDUCAÇÃO, 8, 2010, São Luís. Anais... São Luís: UFMA, 2010.

SILY, Paulo Rogério Marques. Práticas educativas do Museu Nacional do Rio de Janeiro no início do século 20. CONGRESSO BRASILEIRO DE HISTÓRIA DA EDUCAÇÃO, 5, 2008, Aracajú. Anais... Aracajú: UFSE/Unit, 2008.

SOUZA, Rosa Fátima de. Ciência e intuição na escola primária ou como semear o pão do espírito: lições de conteúdo e método. In: SOUZA, Rosa Fátima de. Templos de civilização: a implantação da escola primária graduada no estado de São Paulo (18901910). São Paulo: Unesp, 1998, p. 156-240.

TEIVE, Gladys Mary Ghizoni. Museu escolar ou museu Deyrolle: um dispositivo para a prática das lições de coisas. 2007. Mimeografado.

VIDAL, Diana Gonçalves. A invenção da modernidade educativa: circulação internacional de modelos pedagógicos, sujeitos e objetos no oitocentos. In: CURY, Cláudia Engler; MARIANO, Serioja (org.). Múltiplas visões: cultura histórica no oitocentos. João Pessoa: UFPB, 2009, p. 37-54.

VIDAL, Diana Gonçalves. Museus pedagógicos e escolares: inovação pedagógica e cultura material escolar no Império Brasileiro. In: ALVES, Claudia; MIGNOT, Ana Chrystina (org.). História e historiografia da educação ibero-americana: projetos, sujeitos e práticas. Rio de Janeiro: Quartet/Faperj/SBHE, 2012, p. 197-211.

VIDAL, Diana Gonçalves. O museu escolar brasileiro: Brasil, Portugal e França no âmbito de uma história conectada (final do século 19). In: FERNANDES, Rogério; LOPES, Alberto; FARIA FILHO, Luciano Mendes de (org.). Para a compreensão histórica da infância. Porto: Campo das letras, 2006, p. 239-264.

VIDAL, Diana Gonçalves. Por uma pedagogia do olhar: os museus escolares no fim do século 19. In: VIDAL, Diana Gonçalves; SOUZA, Maria Cecília Cortez Christiano de (org.). A memória e a sombra: a escola brasileira entre o Império e a República. Belo Horizonte: Autêntica, 1999, p. 107-116.

VIÑAO, Antonio. Espaços, usos e funções: a localização e disposição física da direção escolar na escola graduada. In: BENCOSTTA, Marcus Levy Albino (org.). História da educação, arquitetura e espaço escolar. São Paulo: Cortez, 2005, p. 15-47. 
MARILIA GABRIELA PETRY é pedagoga, mestre em Educação pela Universidade do Estado de Santa Catarina. É professora substituta no Colégio de Aplicação da Universidade Federal de Santa Catarina.

Endereço: Servidão Antônio Ludovino dos Santos, 294/3 - 88036-646 Florianópolis - SC - Brasil.

E-mail: marilia_petry@yahoo.com.br.

VERA LUCIA GASPAR DA SILVA é doutora em Educação pela Universidade de São Paulo. Docente no Centro de Ciências Humanas e da Educação da Universidade do Estado de Santa Catarina.

Endereço: Rua Lauro Linhares, 657 - Bloco A, apto. 302 - 88.036-001 Florianópolis - SC - Brasil.

E-mail: vera.gaspar@floripa.com.br.

Recebido em 12 de abril de 2013.

Aceito em 17 de julho de 2013. 